\title{
The effectiveness of family counselling on reducing exposure to secondhand smoke at home among pregnant women in Iran
}

\author{
Farzaneh Soltani', Fariba Barzegar², Gita Sangestani', Ghodratolah Roshanaii ${ }^{3}$, Azam Maleki ${ }^{4}$
}

\begin{abstract}
INTRODUCTION Pregnant women are often exposed to secondhand smoke that affects them and their child. Our aim was to determine the effectiveness of family counselling using the BASNEF model on reducing exposure to secondhand smoke at home among pregnant women.

METHODS A quasi-experimental study was conducted on 103 pregnant women exposed to secondhand smoke. They were selected using a multistage cluster sampling method and allocated into intervention (50 people) and control (53 people) groups. Four family counseling sessions using the BASNEF model were held for the intervention group while the control group received routine care. The outcomes were measured before and at one month after the last session of counselling.

RESULTS In the timeframe before the intervention, the number of days in which there was reported exposure to secondhand smoke was $5.08 \pm$ 1.1 in the intervention group, significantly decreasing to $3.5 \pm 1.6$ after the intervention $(p<0.001)$. No significant change was observed in the control group $(p=0.1)$. Also, the mean scores of all constructs of the BASNEF model increased significantly after the intervention compared to those of the control group $(\mathrm{p}<0.05)$.

CONCLUSIONS Family counseling had a positive effect on decreasing the exposure to secondhand smoke at home among a sample of pregnant women. The BASNEF model is useful for implementing educational care programs in these settings.
\end{abstract}

\begin{abstract}
AFFILIATION
1 Mother and Child Care Research Center, Hamadan University of Medical Sciences, Hamadan, Iran

2 Student Research Center, Hamadan University of Medical Sciences, Hamadan, Iran 3 Modeling of Non-CommunicableDiseases Research Center, Hamadan University of Medical Sciences, Hamadan, Iran

4 Social Determinants of Health Research Center, Zanjan University of Medical Sciences, Zanjan, Iran
\end{abstract}

\section{CORRESPONDENCE TO}

Azam Maleki. Social Determinants of Health Research Center, Zanjan University of Medical Sciences, Zanjan, Iran.

E-mail:malekia41@yahoo.com

\section{KEYWORDS}

health behavior, smoking, pregnant women, secondhand smoke, smoking reduction

\section{Received: 13 June 2019}

Revised: 16 Septmber 2019

Accepted: 16 October 2019

\section{INTRODUCTION}

Exposure to secondhand smoke (SHS) can be through many sources and is linked to adverse health effects ${ }^{1,2}$. Among those exposed to SHS, women and especially pregnant women have been studied widely because of the impact SHS exposure may have on the growing fetus $^{3,4}$. A study among pregnant women in Greece showed that $72 \%$ of women are exposed to SHS in the home and $64 \%$ in the workplace ${ }^{5}$. Also, SHS is associated with effects such as spontaneous abortion, preterm birth, and small for gestational age $\mathrm{e}^{6,7}$. Research has shown that the weight, height and head circumference of newborn babies born from mothers exposed to smoke during pregnancy are lower than those of infants whose mothers were not exposed to SHS $^{8}$. Research further suggests that cognitive and behavioural control disorders in elementary students may be attributable to exposure to smoking before and after childbirth ${ }^{9,10}$.

The extent of exposure to SHS during pregnancy depends on various socioeconomic and cultural conditions ${ }^{5}$. In Iran, women smoke less than men, but the high cigarette smoking rates in men, especially in the western regions of the country ${ }^{11,12}$, 
along with a close family life with relatives, have increased the risk of exposure to SHS for pregnant women. Designing effective interventions for creating a relatively healthy environment for pregnant women and protecting them from adverse maternal and fetal outcomes are among the priorities of healthcare services for pregnant women. Fortunately, pregnancy in all cultures provides an opportunity to change the behaviour of the family, especially when it comes to the health of the infant $^{12,13}$.

Since a change in the behaviour of the smoker spouse is the most effective and logical intervention to reduce the exposure of pregnant women to SHS, the present study was carried out using comprehensive and well-known beliefs, attitudes, subjective norms and enabling factors model (BASNEF), based on which individual's beliefs about the outcomes and benefits of a healthy behaviour are very useful in creating their attitudes towards that behavior. Opinions of other people who live with them are essential and play a significant role in creating the subjective norms towards the desired behaviour ${ }^{14-16}$. BASNEF is a comprehensive and complete model that is adopted to study behaviours, offers plans for change, and defines the factors effective for the individual's decision making ${ }^{14}$.

The aim of the study was to determine the effectiveness of family counselling based on BASNEF model on the times pregnant women are exposed at home to secondhand smoke.

\section{METHODS}

\section{Sampling, setting and participants}

This quasi-experimental study was conducted on 103 pregnant women referred to health centres in Hamadan, Iran, and their smoker spouses. The research population consisted of pregnant women exposed to SHS who attended health centres for prenatal care in Hamadan from October 2017 to May 2018. The samples were drawn through a multi-stage cluster sampling method in two steps. In the first step, Hamadan city was divided into three geographical regions and from each 2 health centres were chosen randomly from a list of health centres; thus 6 health centres were included in the present study. In the second step, one health centre in each region was allocated to the intervention group and the other was allocated to the control group, randomly, to prevent information transfer between the two groups. Participants were chosen randomly among the pregnant women who were eligible for inclusion using the Prenatal Care Information System so that in each health centre 20 people (totally 120 couples) were selected for participation in the study (Figure 1).

The inclusion criteria were the presence of a smoker spouse, healthy singleton pregnancy, and gestational age less than 30 weeks. The exclusion criteria were the presence of medical and obstetric complications, intra-uterine fetal death, divorce, change of residence, and the absence of more than one counselling session.

\section{Instruments}

Data were collected using a demographic questionnaire, and self-constructed questionnaire designed using a similar study for assessing BASNEF model constructs ${ }^{16}$. Self-constructed questionnaire was designed in 5 subscales: 1) spouse's knowledge about the harms of exposure to cigarette smoke in pregnant women and their child, 9 items with

\section{Figure 1. Flow chart of the study}

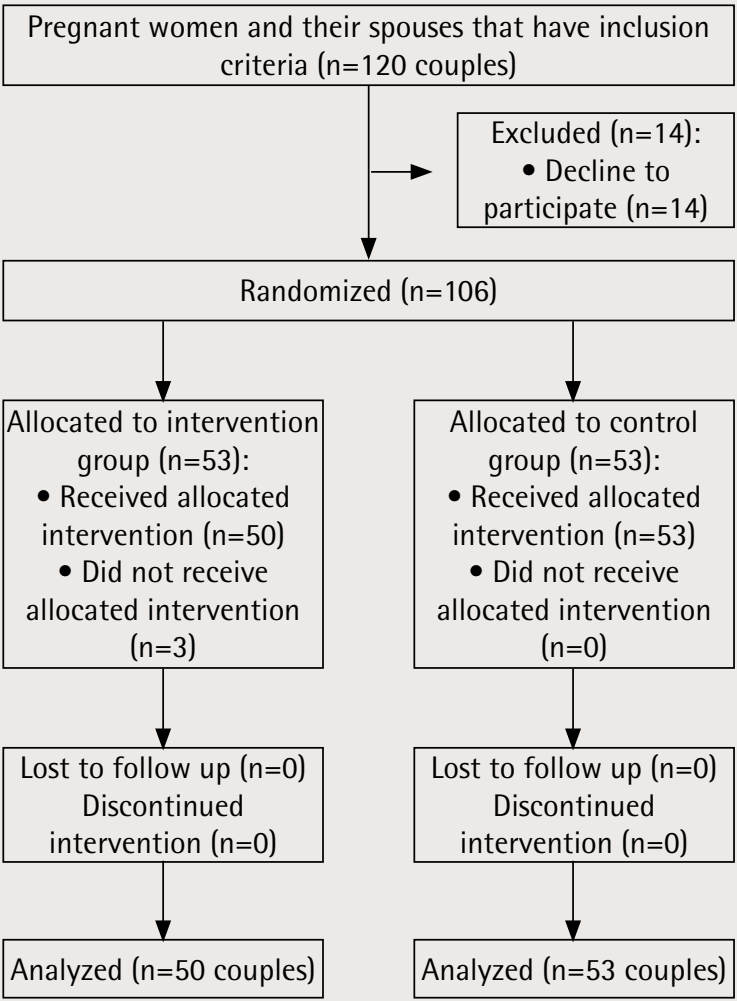


three Likert spectrums; 2) spouse's attitude towards reducing smoking in the presence of his pregnant wife, 13 items with five Likert spectrums; 3 ) subjective norms about reducing smoking in the presence of pregnant women, 7 items with three Likert spectrums; 4) enabling factors of reducing smoking in the presence of pregnant women, 10 items with two Likert spectrums; and 5) behavior outcome evaluation, 6 items with two Likert spectrums. The times of smoking exposure at home were determined using an open-ended questionnaire. The validity of the questionnaires was confirmed through content validity method by eight academic members in reproductive health. Also, using Cronbach's alpha for knowledge items $(a=0.72)$, attitude items $(a=0.70)$, subjective norms items $(a=0.9)$, enabling factors items $(a=0.83)$, behavioral evaluation $(a=0.79)$ and behavioral intention $(a=0.79)$, the reliability of the questionnaire was approved.

\section{Ethical considerations}

This study was approved by the Ethics Committee of Hamadan University of Medical Sciences (IR. UMSHA.REC.1394.254). Participants were informed about the objective of the study, written consent was obtained from each participant, and they were assured of the confidentiality of information. In addition, participants could be excluded whenever they did not want to participate in the study.

\section{Intervention}

The selected pregnant women and their spouses were invited through phone calls for a briefing session wherein written consent to participate in the study was obtained. The questionnaires were completed by pregnant women and their spouses. After necessary coordination, four weekly counselling sessions were held for the intervention group in groups of up to 10 people for $45-60$ minutes, including $45 \mathrm{~min}$ of counselling and 15 min of questions and answers. The consultation sessions in the training class at the health centres were conducted by a researcher (PhD in Reproductive Health and Master of Science in Midwifery). The content of the intervention was family counselling in the form of lectures, group discussion, brainstorming, and questions and answers. Also, educational brochures related to the harms and adverse effects of smoking on pregnant women and unborn children were distributed. The control group received routine prenatal care and the time for completion of questionnaires was set. One month after the end of the intervention, the questionnaires were completed again by the two groups.

\section{Statistical analysis}

Data were analyzed using SPSS software version 16 . The Kolmogorov-Smirnov test was used to ensure the normal distribution of data. Chi-squared test, independent t-test and paired t-test were used to investigate the hypotheses. The significance level was considered $<0.05$.

\section{RESULTS}

The mean age of the mothers in the intervention group was $28.2 \pm 5.7$ years and for the control group it was $29.5 \pm 6.4$ years; the corresponding ages for the spouses were $36.9 \pm 11.0$ years for the intervention group and $40.1 \pm 12.1$ years for the control group. There was no significant difference between the age of pregnant women and their spouses in both control and intervention groups. As noted in Table 1, pregnant woman's employment and education, housing status, the number of smoking individuals at home, spouse's education, duration (years) of spouse's

Table 1. Comparison of demographic characteristics between intervention and control groups, Iran, 2018 (n=103)

\begin{tabular}{|c|c|c|c|c|c|c|}
\hline \multirow[t]{2}{*}{ Variables } & & \multicolumn{2}{|c|}{ Intervention } & \multicolumn{2}{|c|}{ Control } & \multirow[t]{2}{*}{$p$} \\
\hline & & Frequency & $\%$ & Frequency & $\%$ & \\
\hline \multirow[t]{2}{*}{ Pregnant woman's employment } & Employed & 1 & 2 & 7 & 13.2 & \multirow{2}{*}{0.09} \\
\hline & Housewife & 49 & 98 & 46 & 86.8 & \\
\hline \multirow[t]{4}{*}{ Pregnant woman's education } & Illiterate & 0 & 0 & 4 & 7.5 & \multirow{4}{*}{0.11} \\
\hline & Middle school & 30 & 60 & 10 & 18.9 & \\
\hline & Diploma & 16 & 32 & 22 & 41.5 & \\
\hline & University & 4 & 8 & 17 & 32.07 & \\
\hline
\end{tabular}


Table 1. Continued

\begin{tabular}{|c|c|c|c|c|c|c|}
\hline \multirow[t]{2}{*}{ Variables } & & \multicolumn{2}{|c|}{ Intervention } & \multicolumn{2}{|c|}{ Control } & \multirow[t]{2}{*}{$p$} \\
\hline & & Frequency & $\%$ & Frequency & $\%$ & \\
\hline \multirow[t]{2}{*}{ Housing status } & Owner & 40 & 80 & 42 & 79.2 & \multirow{2}{*}{0.92} \\
\hline & Rental & 10 & 20 & 11 & 20.8 & \\
\hline \multirow{3}{*}{$\begin{array}{l}\text { The number of smoking individuals } \\
\text { at home }\end{array}$} & Spouse & 44 & 88 & 39 & 73.6 & \multirow{3}{*}{0.06} \\
\hline & Father-in-law & 6 & 12 & 9 & 17 & \\
\hline & Brother-in-law & 0 & 0 & 5 & 9.4 & \\
\hline \multirow[t]{4}{*}{ Spouse's education } & Illiterate & 4 & 8 & 7 & 23.2 & \multirow{4}{*}{0.55} \\
\hline & Middle school & 27 & 54 & 25 & 47.2 & \\
\hline & Diploma & 14 & 28 & 12 & 22.6 & \\
\hline & University & 5 & 10 & 9 & 16.9 & \\
\hline \multirow{4}{*}{$\begin{array}{l}\text { Duration of spouse's cigarette } \\
\text { smoking in years }\end{array}$} & $1-10$ & 31 & 62 & 30 & 56.6 & \multirow{4}{*}{0.36} \\
\hline & $11-21$ & 13 & 26 & 10 & 18.9 & \\
\hline & $22-32$ & 6 & 12 & 10 & 19.9 & \\
\hline & $\geq 32$ & 0 & 0 & 3 & 5.6 & \\
\hline \multirow[t]{2}{*}{ Spouse's employment } & Self-employed & 46 & 92 & 45 & 84.9 & \multirow{2}{*}{0.26} \\
\hline & Public servant & 4 & 4 & 8 & 15.1 & \\
\hline \multirow{4}{*}{$\begin{array}{l}\text { The number of cigarettes smoked by } \\
\text { the spouse per day }\end{array}$} & $1-10$ & 19 & 38 & 19 & 37.3 & \multirow{4}{*}{0.76} \\
\hline & $11-20$ & 26 & 52 & 29 & 56.9 & \\
\hline & $22-32$ & 2 & 4 & 2 & 3.9 & \\
\hline & $32-40$ & 3 & 6 & 1 & 2 & \\
\hline
\end{tabular}

Table 2. Comparison of number of exposure times of pregnant woman to SHS at home inter and intra two groups before and after intervention, Iran, 2018 (n=103)

\begin{tabular}{|c|c|c|c|c|}
\hline \multirow[t]{2}{*}{ Group } & Before intervention & Mfter intervention & $\begin{array}{l}\text { Statistic } \\
\text { (paired t test) }\end{array}$ & p \\
\hline & Vean $=$ SD & Vean $=$ SD & & \\
\hline Intervention & $5.08 \pm 1.1$ & $3.5 \pm 1.66$ & 9.3 & $<0.001$ \\
\hline Control & $4.02 \pm 1.5$ & $3.7 \pm 1.56$ & 1.4 & 0.1 \\
\hline Statistic (independent t-test) & 0.63 & 4.1 & & \\
\hline $\mathrm{p}$ & 0.4 & $<0.001$ & & \\
\hline
\end{tabular}

cigarette smoking, spouse's employment, and the the intervention and follow-up at home decreased number of cigarettes smoked per day by the spouse, significantly in the intervention group compared to did not statistically differ between the two groups.

Table 2 shows that after the intervention, the mean number of exposure times to SHS between the control group $(\mathrm{p}<0.001)$.

Table 3 shows that after the intervention, there were significant differences between the mean

Table 3. Comparison of scores of BASNEF model constructs inter and intra two groups before and after intervention, Iran, $2018(\mathrm{n}=103)$

\begin{tabular}{|c|c|c|c|c|c|}
\hline \multirow[t]{2}{*}{ Variables } & & Before intervention & Mfter intervention & \multirow{2}{*}{$\begin{array}{l}\text { Statistic } \\
\text { (paired } 1 \text { - test) }\end{array}$} & \multirow[t]{2}{*}{$p$} \\
\hline & & Vean = SD & Mean & & \\
\hline \multirow[t]{2}{*}{ Knowledge } & Intervention & $3.70 \pm 2.40$ & $6.60 \pm 1.94$ & 6.07 & $<0.001$ \\
\hline & Control & $4.3 \pm 1.551$ & $4.94 \pm 2.01$ & 0.53 & 0.29 \\
\hline
\end{tabular}


Table 3. Continued

\begin{tabular}{|c|c|c|c|c|c|}
\hline \multirow[t]{2}{*}{ Variables } & & \multirow{2}{*}{$\begin{array}{l}\text { Before intervention } \\
\text { Mean SD }\end{array}$} & \multirow{2}{*}{$\begin{array}{l}\text { Mfer intervention } \\
\qquad \text { Vean }=\text { SD }\end{array}$} & \multirow{2}{*}{$\begin{array}{c}\text { Statistic } \\
\text { (paired t-test) }\end{array}$} & \multirow[t]{2}{*}{$p$} \\
\hline & & & & & \\
\hline & Statistic (independent t-test) & 1.52 & 4.24 & & \\
\hline & $\mathrm{p}$ & 0.07 & $<0.001$ & & \\
\hline \multirow[t]{4}{*}{ Attitude } & Intervention & $28.16 \pm 7.97$ & $32.58 \pm 5.42$ & 1.8 & 0.04 \\
\hline & Control & $23.83 \pm 6.78$ & $23.92 \pm 9.02$ & 1.83 & 0.06 \\
\hline & Statistic (independent t-test) & 0.92 & 0.18 & & \\
\hline & $\mathrm{p}$ & 0.18 & $<0.001$ & & \\
\hline \multirow[t]{4}{*}{ Enabling factors } & Intervention & $7.86 \pm 1.959$ & $8.96 \pm 1.653$ & 3.65 & 0.001 \\
\hline & Control & $7.45 \pm 1.853$ & $7.49 \pm 1.815$ & 0.54 & 0.11 \\
\hline & Statistic (independent t-test) & 1.1 & 4.28 & & \\
\hline & $\mathrm{p}$ & 0.14 & $<0.001$ & & \\
\hline \multirow[t]{4}{*}{ Subjective norms } & Intervention & $17.2 \pm 2.143$ & $18.82 \pm 1.511$ & 2.23 & 0.03 \\
\hline & Control & $17.36 \pm 2.739$ & $17.19 \pm 2.370$ & 0.37 & 0.07 \\
\hline & Statistic (independent t-test) & 0.7 & 4.13 & & \\
\hline & $p$ & 0.5 & $<0.001$ & & \\
\hline \multirow{4}{*}{$\begin{array}{l}\text { Behavioral } \\
\text { intention of } \\
\text { spouse to reduce } \\
\text { smoking }\end{array}$} & Intervention & $3.44 \pm 1.829$ & $5.76 \pm 1.791$ & 6.5 & $<0.001$ \\
\hline & Control & $3.08 \pm 2.005$ & $3.00 \pm 1.850$ & 0.21 & 0.58 \\
\hline & Statistic (independent t-test) & 0.95 & 7.68 & & \\
\hline & $\mathrm{p}$ & 0.17 & $<0.001$ & & \\
\hline
\end{tabular}

scores of behavioral intention of the spouse to reduce smoking at home, knowledge, attitude, enabling factors, and subjective norms in the intervention group compared to the control group, all statistically significant $(p=0.04)$. After the intervention there were significant differences between the mean scores of all constructs of the BASNEF model in the intervention group $(\mathrm{p}<0.05)$ but these differences were not significant in the control group $(\mathrm{p}>0.05)$.

\section{DISCUSSION}

Our results indicate that family counselling using the BASNEF model has a positive impact on decreasing the times the intervention group where exposed to SHS at home compared to the control group. Enabling factors such as the provision of adequate information, the attitude of the pregnant woman's spouse towards the harmful effects of cigarette smoking on pregnancy outcomes, and identification of subjective norms such as advising other people about reducing smoking at home improved behavioural intention of spouses.

Other consistent studies have supported that behavioural change interventions can lead to increased awareness of harms of exposure to smoking and increased sensitivity of people to reduce exposure to SHS at home ${ }^{17,18}$. Studies in this area are faced with many limitations such as adapting these models to different countries and conditions ${ }^{19}$. Karimiankakolaki et al. ${ }^{4}$ in their study have shown that an educational intervention aiming at reducing SHS exposure of pregnant women could be improved by the level of knowledge, attitude, selfefficacy, and practices of men. The present study showed that if men are involved in safe parenting programs, they can protect the family's health and participate actively in the role of a responsible father to ensure the woman's health during pregnancy. Fathers need to make some changes to adapt to this new role, which is sometimes more difficult because their potential role is often underestimated by their relatives and even healthcare providers ${ }^{20}$. It should be noted that the participation of spouses in ensuring the health of pregnant women is a process of social and behavioural change needed to be created in men so that they undertake more responsibility for the health of mothers and children. 
The participation of men in providing a healthy environment for their pregnant women, especially in developing countries where men are often decision-makers at the family and community level, is important ${ }^{21}$. The need for training to increase participation of fathers in prenatal care resulting in positive effects on maternal and infant health has been shown in numerous studies in different countries $^{22}$. However, it should be noted that the training of men does not guarantee support and participation of spouses during the pregnancy period; changing their viewpoint, attitude and behaviour requires more effective interventions ${ }^{23}$. Thus, the use of behavioural theories in educational interventions can improve the effectiveness of these interventions. In fact, one can be trained to change unhealthy behaviour, but choosing a mentality norm is done by the individual himself and influenced by family, friends, relatives and society. This means that the person evaluates the new behaviour with the level of approval or rejection of those who are important to him, and considering attitudes towards the behaviour and subjective norms leads to decision making in order to adopt the new behaviour ${ }^{24}$. In the meantime, the direct contribution between enabling factors and, in particular, healthcare providers with awareness and behavioural intention, clearly confirms the vital role of these factors in reinforcing preventive behaviours ${ }^{25}$.

\section{Limitations}

This study has some limitations. One of the limitations is the short follow-up interval that was limited to one month. Further studies are recommended to be conducted with longer follow-up intervals. The relatively small sample size was another limitation as it substantially reduced statistical power. Finally, it was quasi-experimental research, so its internal validity may have declined due to the lack of random assignment.

\section{CONCLUSIONS}

Family counselling had a positive effect in decreasing the times of secondhand smoke exposure at home in pregnant women. In addition, using the BASNEF model can be acceptable for implementing educational care programs. Participation of men in maternal and child care provides new opportunities for healthcare providers to train future fathers to ensure a healthy environment for their family.

\section{REFERENCES}

1. Rahimzadeh M, Rastegar H, Fazel Kalkhoran J. Prevalence and causes of tendency to cigarette and water pipe smoking among male and female physical education students in University of Kurdistan. Journal of Health. 2016;7(5):680-686.

2. Mazzone P, Tierney W, Hossain M, Puvenna V, Janigro D, Cucullo L. Pathophysiological impact of cigarette smoke exposure on the cerebrovascular system with a focus on the blood-brain barrier: expanding the awareness of smoking toxicity in an underappreciated area. Int J Environ Res Public Health. 2010;7(12):4111-4126. doi:10.3390/ijerph7124111

3. Roigé-Castellví J, Murphy M, Hernández-Martínez G, Solé-Navais P, Cavallé-Busquets P, Fernández-Ballart J, et al. The effect of prenatal smoke exposure on child neuropsychological function: a prospective motherchild cohort study. J Reprod Infant Psychol. 2019:1-13. doi:10.1080/02646838.2019.1580350

4. Karimiankakolaki Z, Mahmoodabad SSM, Kazemi A, Fallahzadeh H. Designing an educational intervention on second-hand smoke in smoker men on the exposure of pregnant wives: a protocol for a randomized controlled trial. Reprod Health. 2019;16(1):11. doi:10.1186/s12978-019-0673-1

5. Vardavas CI, Patelarou E, Chatzi L, Roumeliotaki T, Sarri K, Murphy S, et al. Factors associated with active smoking, quitting, and secondhand smoke exposure among pregnant women in Greece. J Epidemiol. 2010;20(5):355-362. doi:10.2188/jea.je20090156

6. Mojibyan M, Karimi M, Bidaki R, Rafiee P, Zare A. Exposure to second-hand smoke during pregnancy and preterm delivery. Int J High Risk Behav Addict. 2013;1(4):149-153. doi:10.5812/ijhrba.7630

7. Khader Y, Abdelrahman M, Abdo N, Awad S, Al-Sharif M, Elbetieha A, Malkawi M. Exposure to air pollution and pregnancy outcomes in the East Mediterranean Region: a systematic review. Int. J. Pediatr. 2016;4(1):1255-1271. doi:10.22038/IJP.2016.6285

8. Howe LD, Matijasevich A, Tilling K, Brion M-J, Leary SD, Smith GD, et al. Maternal smoking during pregnancy and offspring trajectories of height and adiposity: comparing maternal and paternal associations. Int J Epidemiol. 2012;41(3):722-732. doi:10.1093/ije/dys025

9. Makadia LD, Roper PJ, Andrews JO, Tingen MS. Tobacco use and smoke exposure in children: new trends, harm, and strategies to improve health outcomes. Curr Allergy Asthma Rep. 2017;17(8):55. doi:10.1007/s11882-017-0723-0

10. Brook JS, Zhang C, Fagan P. Exposure to parental cigarette smoking and child problem behaviors: A longitudinal study. J Child Fam Stud. 2008;17(3):372384. doi:10.1007/s10826-007-9147-0 
11. Moosazadeh M, Salami F, Movahednia M, Amiri MM, Afshari M. Prevalence of smoking in northwest Iran: a meta-analysis. Electron Physician. 2014;6(1):734-740. doi:10.14661/2014.734-740

12. Soltani F, Majidi M, Shobeiri F, Parsa P, Roshanaei GH. Knowledge and attitude of men towards participation in their wives' perinatal care. International Journal of Women's Health and Reproduction Sciences. 2018;6(3):356-362. doi:10.15296/ijwhr.2018.58

13. Mullany BC. Barriers to and attitudes towards promoting husbands' involvement in maternal health in Katmandu, Nepal. Soc Sci Med. 2006;62(11):2798-2809. doi:10.1016/j.socscimed.2005.11.013

14. Momenabadi V, Iranpour A, Khanjani N, Mohseni M. Effect of educational intervention on water pipe behaviour of students in dormitories of Kerman Medical University: BASNEF Model. 2015;23(3):262-267. doi:10.1080/14659891.2017.1394376

15. Pollak KI, Denman S, Gordon KC, Lyna P, Rocha P, Brouwer RN, et al. Is pregnancy a teachable moment for smoking cessation among US Latino expectant fathers? A pilot study. Ethn Health. 2010;15(1):47-59. doi:10.1080/13557850903398293

16. Lee AH. A pilot intervention for pregnant women in Sichuan, China on passive smoking. Patient Educ Couns. 2008;71(3):396-401. doi:10.1016/j.pec.2008.03.014

17. Safdar N, Zahid R, Shah S, Cameron I, Fatima R, Qureshi H, Kamran S. TB patients learning about second hand smoke (TBLASS): a pilot individual randomised controlled trial. SpringerPlus. 2013;2(1):556. doi:10.1186/2193-1801-2-556

18. Siddiqi K, Khan A, Ahmad M, Dogar O, Kanaan M, Newell JN, et al. Action to stop smoking in suspected tuberculosis (ASSIST) in Pakistan: a cluster randomized, controlled trial. Ann Intern Med. 2013;158(9):667-675. doi:10.7326/0003-4819-158-9-201305070-00006

19. Dherani M, Zehra SN, Jackson C, Satyanaryana V, Huque $\mathrm{R}$, Chandra $\mathrm{P}$, et al. Behaviour change interventions to reduce second-hand smoke exposure at home in pregnant women-a systematic review and intervention appraisal. BMC Pregnancy Childbirth. 2017;17(1):378. doi:10.1186/s12884-017-1562-7

20. World Health Organization. Programming for male involvement in reproductive health. Geneva, Switzerland: World Health Organization; 2002. https://apps.who.int/ iris/bitstream/handle/10665/67409/WHO_FCH_RHR_ 02.3.pdf;jsessionid=3 D 96F845C0CE9821349 70DB7483F6684? sequence=1. Accessed June 13, 2019.

21. United Nations Population Fund. Partnering: A new approach to sexual and reproductive health. New York, NY: United Nations Population Fund; 2000. https://www. unfpa.org/sites/default/files/pub-pdf/partnering_eng. pdf. Accessed June 13, 2019.

22. Dheensa S, Metcalfe A, Williams RA. Men's experiences of antenatal screening: a metasynthesis of the qualitative research. Int J Nurs Stud. 2013;50(1):121-133. doi:10.1016/j.ijnurstu.2012.05.004

23. Aborigo RA, Reidpath DD, Oduro AR, Allotey P. Male involvement in maternal health: perspectives of opinion leaders. BMC Pregnancy Childbirth. 2018;18(1):3. doi:10.1186/s12884-017-1641-9

24. Akbarzadeh M, Moattari M, Abootalebi M. Effect of the basnef model on maternal-fetal attachment in the pregnant women referring to the prenatal clinics affiliated to shiraz university of medical sciences. Iranian Journal of Neonatology. 2017;8(3):31-37. doi:10.22038/IJN.2017.20521.1229

25. El-Mohandes AA, Kiely M, Blake SM, Gantz MG, El-Khorazaty MN. An intervention to reduce environmental tobacco smoke exposure improves pregnancy outcomes. Pediatrics. 2010;125(4):721-728. doi:10.1542/peds.2009-1809

\section{ACKNOWLEDGEMENTS}

The authors acknowledge the support of the Student Research Center of Hamadan University of Medical Sciences, the staff of the participating health centres for their collaboration, and the mothers for their participation.

\section{CONFLICTS OF INTEREST}

The authors have completed and submitted the ICMJE Form for Disclosure of Potential Conflicts of Interest and none was reported.

\section{FUNDING}

There was no source of funding for this research.

\section{AUTHORS' CONTRIBUTIONS}

FS is the first supervisor and also contributed to the design of the study, and reporting of the result. The conception, design of the study, and data collection process were undertaken by FB and GS. Reporting were also supervised by GHR and AM. All authors contributed in drafting the article, revising it and in agreement with final version of the manuscript to be submitted to the journal and they also met the criteria of authorship.

\section{PROVENANCE AND PEER REVIEW}

Not commissioned; externally peer reviewed. 